\title{
Severe Pain in Chronic Pancreatitis Patients: Considering Mental Health and Associated Genetic Factors
}

This article was published in the following Dove Press journal: Journal of Pain Research

\author{
Ellyn K Dunbar' \\ Jami L Saloman (iD) ${ }^{2}$ \\ Anna Evans Phillips ${ }^{3}$ \\ David C Whitcomb (D) ${ }^{4}$ \\ 'Departments of Human Genetics and \\ Medicine, Division of Gastroenterology, \\ Hepatology and Nutrition, University of \\ Pittsburgh, Pittsburgh, PA, USA; \\ ${ }^{2}$ Departments of Neurobiology and \\ Medicine, Division of Gastroenterology, \\ Hepatology and Nutrition, Pittsburgh \\ Center for Pain Research, University of \\ Pittsburgh, Pittsburgh, PA, USA; \\ ${ }^{3}$ Department of Medicine, Division of \\ Gastroenterology, Hepatology and \\ Nutrition, University of Pittsburgh, \\ Pittsburgh, PA, USA; ${ }^{4}$ Departments of \\ Human Genetics, Cell Biology and \\ Molecular Physiology, and Medicine, \\ Division of Gastroenterology, Hepatology \\ and Nutrition, Pittsburgh Center for Pain \\ Research, University of Pittsburgh, \\ Pittsburgh, PA, USA
}

Correspondence: David C Whitcomb Division of Gastroenterology, Hepatology and Nutrition, University of Pittsburgh and UPMC, Room 40I.4, 3708 Fifth Ave, Pittsburgh, PA, 15213, USA

Tel + 4125789515

Email whitcomb@pitt.edu

\begin{abstract}
Pain is the most distressing and disruptive feature of recurrent acute pancreatitis (RAP) and chronic pancreatitis (CP) resulting in low quality of life (QOL) and disabilities. There is no single, characteristic pain pattern in patients with RAP and CP. Abdominal imaging features of $\mathrm{CP}$ accurately reflect morphologic features but they do not correlate with pain. Pain is the major driver of poor quality of life (QOL) and it is the constant pain, rather than intermittent pain that drives poor QOL. Furthermore, the most severe constant pain experience in CP is also a complex condition. The ability to target the etiopathogenesis of severe pain requires new methods to detect the exact pain mechanisms in an individual at cellular, tissue, system and psychiatric levels. In patients with complex and severe disease, it is likely that multiple overlapping mechanisms are simultaneously driving pain, anxiety and depression. Quantitative sensory testing (QST) shows promise in detecting alterations in central processing of pain signals and to classify patients for mechanistic and therapeutic studies. New genetic research suggests that genetic loci for severe pain in CP overlap with genetic loci for depression and other psychiatric disorders, providing additional insights and therapeutic targets for individual patients with severe CP pain. Well-designed clinical trials that integrate clinical features, QST, genetics and psychological assessments with targeted treatment and assessment of responses are required for a quantum leap forward. A better understanding of the context and mechanisms contributing to severe pain experiences in individual patients is predicted to lead to better therapies and quality of life.
\end{abstract}

Keywords: pancreatitis, pain management, mental health, depression, genetic research

\section{Introduction}

Chronic pancreatitis (CP) is a pathologic fibro-inflammatory syndrome of the pancreas that results in persistent pathologic responses to parenchymal injury or stress, manifesting as debilitating abdominal pain in up to $90 \%$ of patients. ${ }^{1,2} \mathrm{CP}$ is the end-stage of a pathogenic process that typically includes episode(s) of acute pancreatitis (AP) or recurrent AP (RAP). The clinical features of the established and end stages of CP differ among patients as the failure or dysfunction of the different cell types involved in pancreatic physiology reveals different amounts of resilience or susceptibility to recurrent or sustained injury or stress. Thus, the appearance of the pancreas on cross-sectional abdominal imaging measures fibrosis, atrophy, cysts, calcifications, etc. but cannot predict whether or not the patient has exocrine pancreatic insufficiency (EPI), ${ }^{3}$ diabetes mellitus $(\mathrm{DM})^{4}$ or pain. ${ }^{5}$ 
Pain in RAP and CP significantly and negatively impacts the quality of life (QOL) and results in progressively higher rates of disability. ${ }^{6,7}$ Pain in CP is multifactorial and is notoriously challenging to treat. ${ }^{8-11}$ Currently, pain management in RAP and CP is based on questionnaire-based measurements of pain severity ${ }^{12}$ and analgesic therapy is based on general recommendations from the World Health Organization on the treatment of chronic pain. ${ }^{13}$ Treatment options in CP focus on symptom relief with most $\mathrm{CP}$ patients being prescribed opioids for the treatment of their pain. ${ }^{13}$ In some patients, ductobstructing pancreatic duct stones or strictures can be treated with invasive treatments (endotherapy, extracorporeal shockwave lithotripsy [ESWL] or surgery) to relieve suspected intraductal hypertension, although these interventions are effective in only a subset of patients..$^{9,14-17}$ Total pancreatectomy with islet cell auto-transplantation (TPIAT) has been offered as radical treatment and the last resort to patients with severe, unmanageable pain. ${ }^{18}$ Unfortunately, these current pain management strategies for $\mathrm{CP}$ are suboptimal. National and international scientific and clinical teams are working to develop methods for assessing and treating pain - an important unmet need in $\mathrm{CP}^{19-21}$

Pain is a complex experience that includes both sensory input to the brain and the interpretation of the pain based on many adaptive and psychological factors. The experience of pain and impact on QOL can be markedly exacerbated by the coexistence of psychiatric diagnoses such as depression. ${ }^{22-24}$ Our knowledge of predisposing genetic risks and how to treat mental health issues in patients with $\mathrm{CP}$ are in their early stages, but understanding the interaction between mental health and pancreatic pain may be very important for optimal patient management in the future. We conducted a literature search in PubMed for relevant English-language articles published before December 1, 2020. Search terms included chronic pancreatitis and pain, and each of the followings: genetics, genetic mutations, genetic polymorphisms, risk factors, mental health, anxiety, depression, mood disorder, neural networks and pain, neural networks and mood disorders, anxiety and depression, psychiatric condition, mood disorder, cannabinoids, opioids, and gabapentinoids. Publications on chronic pancreatitis and pain were reviewed in depth, and additional references from those publications were reviewed for relevant content and included. Case reports and case series were excluded. All other relevant articles were reviewed by the author group and those with the greatest relevance were considered for inclusion.

\section{Clinical Characteristics of Pancreatic Pain}

Pain is a subjective and emotional response to actual or potential tissue damage; therefore, objective methods of pain assessment based on end-organ pathology alone are impossible. ${ }^{25}$ Furthermore, assessment of pancreatic pain is challenging due to the multiple pathologies contributing to the overall experience, including pancreatic parenchymal oxidative/metabolic stress, inflammation, neuritis/neuropathy, pancreatic ductal obstruction, ischemia, and alterations in peripheral and central neural pain processing. ${ }^{8}$ In addition, there are emotional aspects of pain that are likewise complex. Multiple general pain assessment tools have been used to assess some aspects of pain in CP. CP-specific tools now include the Comprehensive Pain Assessment Tool for CP (COMPAT) and Pancreatic Quality of Life Instrument (PANQOLI) and they show promise for future evaluation and classification of characteristics specific to $\mathrm{CP}^{26,27}$ However, these tools cannot decipher or specify the mechanisms of pain and how risk factors interact with these mechanisms or how they affect the QOL.

Historically, pain in CP was divided into two specific patterns (Types A and B) by Ammann et al in their 1999 study of alcoholic $\mathrm{CP}$, which was widely adopted for the clinical classification of CP pain. ${ }^{28}$ Type A pain was characterized by short-lived pain episodes lasting fewer than 10 days, and separated by long pain-free intervals. Type B pain was characterized by prolonged periods of daily pain, punctuated by clusters of recurrent, severe pain exacerbations. Some patients experience both types of pain: of the 207 patients in their series, all patients experienced at least one attack of Type A pain, but only 116 (56\%) reported experiencing Type B pain. B-type pain was associated with pancreatic pseudocysts (or walled-off necroses), cholestasis, and presumptive pancreatic ductal hypertension. ${ }^{28}$

A 2011 publication by Mullady and the investigators of the North American Pancreatitis Study (NAPS2) group evaluated over $400 \mathrm{CP}$ patients of all etiologies from 20 tertiary medical centers across the United States, and asked patients to self-identify their pattern of pain from 5 choices based on temporal nature (intermittent versus constant) and severity (mild, moderate, severe) (Table 1). ${ }^{29}$ Patients with constant pain (as compared to intermittent) had higher rates of disability, hospitalization, pain medication use, and lower quality of life as 
Table I Possible Choices for the Self-Designation of Pain Pattern and Severity Level Experienced by Patients with Chronic Pancreatitis from the North American Pancreatitis Study (NAPS2). Patients Were Asked to Choose One of the Five Patterns (A Through E) That Best Described Their Experience. Letters in the "Pattern" Column Identify the Label Assigned to Each Type of Pain. Table Modified to Include Category $O$ This Expands the Classifications to Include "Painless" Chronic Pancreatitis, a Well-Described Phenomena

\begin{tabular}{|l|l|}
\hline Pattern & Definition \\
\hline O & No pain \\
\hline A & Episodes of mild/moderate pain—but no constant pain \\
\hline B & Constant mild/moderate pain—but no episodes of pain \\
\hline C & Episodes of severe pain—but no constant pain \\
\hline D & $\begin{array}{l}\text { Constant mild/moderate pain PLUS episodes of more } \\
\text { severe pain }\end{array}$ \\
\hline E & Constant severe pain \\
\hline
\end{tabular}

Note: Reproduced from Gut, Mullady DK, Yadav D, Amann ST, et al. Type of pain, pain-associated complications, quality of life, disability and resource utilisation in chronic pancreatitis: a prospective cohort study, 60(I):77-84. Copyright 201 I, with permission from BMJ Publishing Group Ltd. ${ }^{29}$

measured by the Short Form 12 (SF-12) instrument. A similar pattern, but at an intermediate level is seen with patients with RAP. ${ }^{7}$ In addition to the features described above, patients with constant pain were more likely to have an alcoholic etiology of $\mathrm{CP}$ than their counterparts with intermittent pain. ${ }^{6,29}$ Interestingly, approximately $10 \%$ of patients with $\mathrm{CP}$ have no pain for reasons that are not yet understood. ${ }^{30}$ The variability indicates unidentified intrinsic factors, such as genetic variants, psychiatric or other risk factors that affect the nature and severity of pain signaling since the imaging features of pancreatitis do not correlate with $\mathrm{CP}$ pain pattern or severity. ${ }^{5}$

\section{Biology of Pancreatic Pain}

The variability in pain experiences and responses to treatment indicates that multiple mechanisms are involved in the detection, transmission, interpretation and responses to pain generation between individuals. While there is complex circuitry of the integrated sensory system in humans, pancreatic pain begins with pancreas-derived noxious stimuli. ${ }^{31}$ However, central processing including psychological and emotional states also shapes the pain experience.

A brief summary of local mechanisms of pain is addressed here (Table 2). A more in-depth discussion of
Table 2 Categories of Contributing Factors and Underlying Etiologies That Influence the Experience of Pain in Patients with Chronic Pancreatitis

\begin{tabular}{|l|}
\hline $\begin{array}{l}\text { Contributors to the Experience of Pain in Chronic } \\
\text { Pancreatitis }\end{array}$ \\
\hline Tissue Injury \\
\hline Cellular Metabolic Stress (Oxidative, etc) \\
\hline Inflammation \\
\hline Pancreatic Duct Obstruction \\
\hline Neuropathy \\
\hline Central Nervous System Changes \\
\hline Psychiatric Comorbidities \\
\hline
\end{tabular}

the central and psychological aspects of pain is discussed in detail below.

\section{Injury and Pain in Acute Pancreatitis}

Acute pancreatitis typically triggers pain through initial injury signals from acinar cells that are followed by an inflammatory response that subsequently activates pancreatic afferents. The pain of acute pancreatitis is typically severe, characterized as sharp or stabbing in nature. As inflammation evolves the patient also develops nausea and even vomiting. The pain of acute pancreatitis may also be connected to visceral ischemia in more severe acute pancreatitis with capillary leak, hypovolemia and multi-organ dysfunction. ${ }^{32}$ Marked improvement in AP pain may occur with adequate fluid resuscitation (personal observation).

\section{Inflammatory Pain}

Pain of ongoing inflammation is generally not sharp and stabbing as in acute injury, but rather gnawing, burning, nauseating or tender. If pain is being driven by oxidative or metabolic stress, then antioxidants are often useful in treating pain. ${ }^{33-37}$ In some animal and human studies, the pain of pancreatic, as well as other types of visceral inflammation, is also effectively treated with cannabinoids. ${ }^{38-40}$ Further research is needed to evaluate these types of therapy specifically for pancreatic pain.

Chronic pancreatitis is a complex syndrome in which patients have variable types and degrees of pathology, such as fibrosis, duct dilatation, calcifications, atrophy or inflammatory masses. The importance of inflammation in pain can be argued by the fact that pancreatic atrophy is often painless, while even moderate inflammation can be painful. 
Inflammatory masses in the head of the pancreas are typically highly painful and debilitating, more common in alcohol etiologies, and are resistant to most non-surgical management approaches. ${ }^{41-43}$

\section{Obstruction/Pressure}

Obstruction of the pancreatic duct can also cause pain. This type of pain may be more colicky or steady and is often linked to signs of obstruction on abdominal imaging studies, including endoscopic retrograde cholangiopancreatography (ERCP). This type of pain may be alleviated by endoscopic procedures, such as ESWL to break up intraductal stones, ERCP to clear the pancreatic duct and cross strictures with pancreatic duct stenting, or by surgical drainage procedures. ${ }^{9,44,45}$

\section{Neuritis and Neuropathies}

Another source of severe pain arising from the pancreas in painful CP is neuritis-the infiltration of the nerves by leukocytes. This process may also be accompanied by nerve hypertrophy and is typically seen in inflammatory masses and is resistant to standard treatments. ${ }^{46-51}$ Surgical resection may be required, and it should be done before there are permanent changes in the central nervous system., ${ }^{8,52}$

The major differential diagnosis in patients with pancreatitis-like pain is distinguishing between RAP, CP and functional abdominal pain (ie irritable bowel syndrome). Recent reports suggest that specific criteria on CT imaging of the pancreas can be useful. ${ }^{53}$ The differential diagnosis of less common types of abdominal pain that mimic pancreatic pain is given elsewhere. ${ }^{54-56} \mathrm{~A}$ rapid change in pain pattern, especially with new weight loss or development of diabetes, may be a sign of pancreatic cancer, ${ }^{57,58}$ especially since patients with $\mathrm{CP}$ are at high risk of developing pancreatic cancer. ${ }^{52,59,60}$

\section{Central Sensitization/Central Pain}

Patients with severe, painful CP that is not controlled within 2-3 years often develop a syndrome called central sensitization or central pain. ${ }^{8-10}$ In its early stages before spreading to the central nervous system, neurologic changes may be confined to the spinal cord and peripancreatic nerves of the pancreatic viscerotome, resulting in a condition termed segmental sensitization. ${ }^{61}$

There are multiple localized and integrated brain networks involved in the perception of physical and psychological pain. Activation of nociceptors is an alarm signal to the brain. Under chronic pain conditions, a constant alarm drives functional reorganization of the brain. As a result, patients with chronic pain can exhibit a range of cognitive and neurological deficits. Indeed, different chronic pain conditions are associated with distinct patterns of brain activity and morphological alterations (reviewed elsewhere). ${ }^{62-64}$

\section{Overlap of Pain and Emotion Areas of the Brain}

Chronic pain also drives changes in psychological processes including perception, attention, mood, motivation, learning and memory. ${ }^{65}$ Changes in corticolimbic networks, which are involved in these psychological processes are direct predictors of chronic pain. ${ }^{66,67}$ With the transition from acute to chronic pain, the brain representation shifts toward emotional circuits. ${ }^{68}$ There is also a decrease in functional connectivity between the medial prefrontal cortex and hippocampus. ${ }^{69}$ Patients with chronic low back pain or pain from irritable bowel syndrome also exhibit reduced gray matter volume in the striatum, particularly the nucleus accumbens. ${ }^{66,70}$ Chronic pain patients with reduced striatal function exhibit a dampening of incentive-related behaviors, a common feature of those with major depression. ${ }^{71}$ Patients with painful craniomandibular disorder show increased activation of the insula and concomitant increases in anxiety, both of which are reversed with successful therapy. ${ }^{72}$ Similar changes may accompany pain from $\mathrm{CP}$.

\section{Effects of Emotions on Pain Perception}

While chronic pain can drive changes in brain activity that influence mood, so too can cognitive or emotional state also directly modulate pain. For instance, subjects expecting analgesia failure report no relief from a clinically efficacious dose of opioids. ${ }^{73}$ Following induction of a sad state, subjects report significantly higher pain ratings as compared to a neutral mood state. ${ }^{74}$ In patients with major depression, thermal pain thresholds are significantly increased and they exhibit altered brain activity patterns. ${ }^{75,76}$ Like chronic pain patients, people with major depressive or anxiety disorder exhibit altered functional connectivity (see reviews) ${ }^{77-79}$ For example, in anticipation of a painful stimulus, patients exhibit increased activity in the amygdala and decreased activity in the anterior cingulate and prefrontal cortices. ${ }^{80}$ This suggests that patients with major depressive disorder 
have increased emotional reactivity during anticipation of pain that may impair their ability to modulate pain experience. Pain, anxiety, or depression can lead to alterations in signaling in overlapping brain regions, including hippocampus, amygdala, striatum, anterior cingulate cortex, and medial prefrontal cortex. Since the same circuits are utilized for pain and psychological processing it is not surprising that there is significant comorbidity in these patient populations.

\section{Variation in Physical Pain Perception and Processing Among Patients with CP}

Clinicians recognize that pain patterns do not always follow the pathologic appearance of the pancreas on imaging studies. ${ }^{5}$ Some patients appear to be hypersensitive to various types of pain, while others either feel less pain with the same injury or are less likely to externalize their pain. The variable clinical features of pain (Table 1) and the multiple mechanisms of pain (Table 2) must be connected to decipher the pain drivers and potentiators in individual patients. New clinical tools are needed to sort out the components of the pain syndrome in individual patients so that the best treatment can be given to each person. An algorithm for the treatment of painful chronic pancreatitis was previously developed through a consensus agreement of the major pancreatic research societies. ${ }^{9}$ Figure 1 is a modification of this guidance on CP treatment using currently available therapies.

\section{Quantitative Sensory Testing}

While pain is a subjective experience, nociception is defined by the International Association for the Study of Pain as the neural process of encoding noxious stimuli. ${ }^{83}$ Thus, unlike pain, nociception is amenable to evaluation by systematic testing. Quantitative sensory testing (QST) is a method used to measure nociception by administering a series of external stimuli of controlled intensity. A collaboration of researchers has developed and tested a pancreas-specific quantitative sensory testing protocol (P-QST) that can separate patients into three phenotypes suggestive of normal nociception, altered nociception at the level of the pancreatic viscerotome, and widespread hyperalgesia suggestive of systemic central sensitization. ${ }^{13}$ Although this method does not test pain per se, it can assess alterations in neural signaling. Widespread hyperalgesia in CP patients has been associated with higher pain intensity, constant pain, lower QOL, and lower physical functioning. ${ }^{61}$ Of note, these associations were seen as independent of any psychiatric comorbidities.

\section{$\mathrm{CP}$ as a Complex Gene-Environment- Metabolic Disease}

Understanding $\mathrm{CP}$ requires the transition from a traditional monolithic view of disease (eg WHO pain step-up model of pain management) to a more holistic view ${ }^{81}$ where each case is an independent combination of multiple risk factors $^{82}$ that act in a pathogenic way to cause disease. $^{83-85}$ While the science of the new approach is beyond the scope of this review, the importance of genetics cannot be underestimated. Indeed, the role of genetic variants in drug-metabolizing genes (pharmacogenetics) is well established and is highly relevant for variable responses and even toxic outcomes in the treatment of pain and depression. ${ }^{86-91}$

Genetic variant evaluation is a powerful tool since it can direct the analyst to specific mechanisms in the body that are likely to be dysfunctional under injury or stress, and other systems that are likely to be normal. ${ }^{92}$ These tools are therefore most useful early in the course of disease before the damage of poorly managed pathogenic pathways becomes irreversible. ${ }^{93}$ The primary utility of genetic testing is to identify risk factors contributing to pancreatitis etiology and the mechanism of disease. A secondary analysis is indicated as pharmacologic therapies are being considered for pain management including genetic loci and variants associated with psychiatric disorders as well as pharmacogenetics to select medications that are most likely to be effective at standard or modified doses (Figure 1, orange box)

Future expert physicians and health care workers must adopt a more sophisticated analysis of patients where multiple risk factors (ie factors that are neither necessary nor sufficient to cause disease alone but are more common in patients with disease than controls) combine in ways that can be modeled to determine their combined effect on cell disorders and disease development. ${ }^{83}$ Thus, classic genetic testing reports are inadequate. Integration of all known factors must be considered within appropriate contexts so that strong clinical decision support reports are available to provide guidance. ${ }^{92}$ The information below may provide critical insights into these complex 


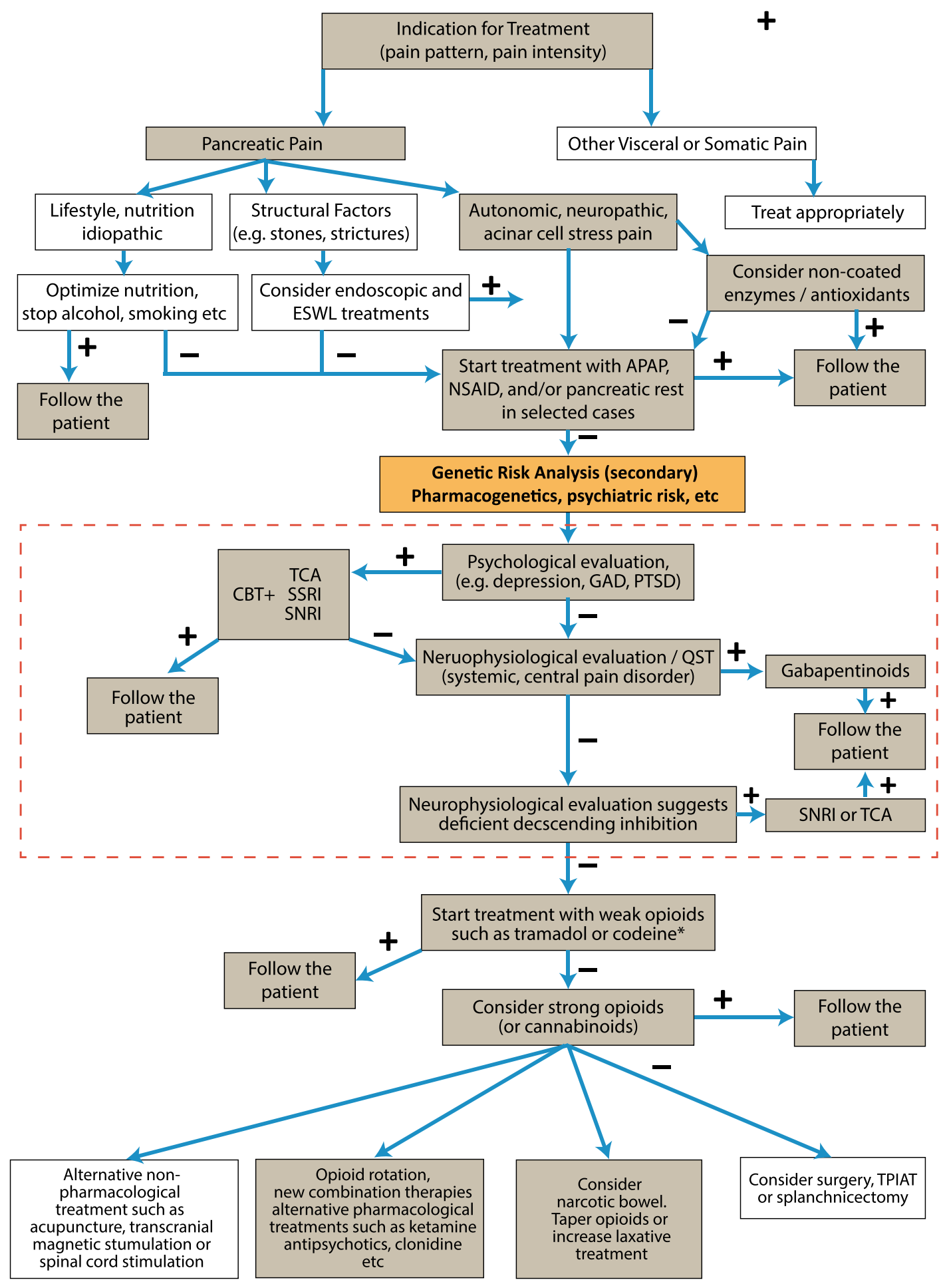

Figure I Clinical pain management algorithm for pharmacological treatment (tan boxes) of pain in chronic pancreatitis highlighting the steps related to management of psychiatric disease overlay (red dash-line box). Combination therapies may be necessary. When initial treatment fails, pharmacogenetic (eg CYP2D6) and genetic analysis of high-risk psychiatric loci should be reviewed at this point (orange box). Treatment with antidepressants is currently guided by psychological evaluation including assessment of catastrophizing, depression, etc., but genetic testing for genetic predisposition to severe pain linked to psychiatric disorders may guide specific therapy especially when linked to cognitive behavioral therapy (CBT). Treatment shall be individualized due to major differences in receptor properties and analgesic mechanisms between patients. Opioids shall be avoided if possible due to the major side effects on the gastrointestinal tract, etc., but in severe pain they may be prescribed for limited periods and the physician shall always be aware of opioid-induced bowel dysfunction and hyperalgesia (narcotic bowel). *The FDA-approved drug label for codeine has a black box warning that respiratory depression and death have occurred in children who had evidence of being CYP2D6 ultra-rapid metabolizers. Reprinted from Pancreatology, I7(5), Drewes AM, Bouwense SAW, Campbell CM, et al. Guidelines for the understanding and management of pain in chronic pancreatitis, 720-73I. Copyright (2017), with permission from Elsevier. 9

Abbreviations: APAP, acetaminophen; SNRI, serotonin and norepinephrine reuptake inhibitors; SSRI, selective serotonin reuptake inhibitors; TCA, tricyclic antidepressants. 
mechanisms so that useful reports including clinical decision support recommendations will be available in the future.

\section{Pancreatic Pain and Mental Health}

Depression, anxiety and physical pain often occur concomitantly, and their co-occurrence can have an exponentially detrimental effect. ${ }^{22,94-97}$ Approximately $85 \%$ of patients suffering from chronic pain also suffer from depression, and between $30 \%$ and $60 \%$ of chronic pain sufferers also experience anxiety. ${ }^{22,96,98}$ The combination of pain with depression and/or anxiety is very difficult to treat, and increases suicide risk as compared to individuals without pain. ${ }^{22}$

Pain in CP significantly and negatively impacts the quality of life and results in higher rates of disability. ${ }^{6}$ In a recent cohort study of 171 patients with CP by Phillips et al, anxiety and depression (as defined by Hospital Anxiety and Depression Scale scores of $>7$ ) were present in $46.8 \%$ and $38.6 \%$ of patients, respectively. ${ }^{99}$ Overlap of anxiety and depression was seen in $29 \%$ of patients. Patients who had anxiety or depression reported higher prevalence rates of pain, pain severity, and interference of pain with their daily activities compared to their nonanxious, non-depressed counterparts. Patients with depression were more likely to be taking opioids. The presence of anxiety or depression was also associated with lower QOL as measured by the European Organization for the Treatment of Cancer Quality of Life Questionnaire global health score and subscores. The presence of pain (intermittent or constant) was independently associated with decreased global health, and an association between global health status and depression was confirmed independently of pain. ${ }^{99}$

In the previously mentioned North American Pancreatitis Study (NAPS2) of 414 patients with CP, patients with constant pain exhibited lower physical and mental health scores than their counterparts with intermittent pain (Table 1, BDE, constant vs AC, intermittent). ${ }^{29}$ Additionally, non-alcoholic chronic pancreatitis patients with depression often report experiencing higher levels of pain and lower quality of life. ${ }^{100}$

The presence of a psychiatric comorbidity or substance use disorder in any patient may increase the risk of the patient developing the other. ${ }^{101-103}$ Although a unidirectional causal association has not been established there exists a strong association between addiction to alcohol, anxiety, posttraumatic stress, and depression. ${ }^{101-106}$ This connection, as well as that between smoking, anxiety and depression, are of unique importance in painful CP. Alcohol and tobacco negatively impact RAP and $\mathrm{CP}$ as well as promote progression of the former to the latter. ${ }^{107}$ Active smoking status in CP patients has been seen to associate with lower physical and mental quality of life and more frequent use of antidepressants. ${ }^{6,108,109}$

\section{Mental Health in CP Patients and Links to the Genetics of Pain}

The mental aversion of pain is encoded in brain regions that also process reward and motivation. Evidence from preclinical animal studies suggests that the neuroplasticity in corticolimbic circuits underlies the anxiety and depression symptoms that are often associated with chronic pain. ${ }^{110}$ In pain patients, striatal hypofunction correlates with mood alterations. ${ }^{71}$ With the overlap in both prefrontal cortex and limbic pathways, it is not surprising that functional alterations driven by either pain or mood disorders affect the manifestation of the other. However, the fact that there are marked effects in some people and not others is not defined by brain activity alone. New evidence is emerging that genetic risk for depression and anxiety plays a major role in the psychiatric phenotypes, and that co-existence of genetic risk for depression and anxiety in patients with RAP and CP results in a more severe pain experience.

To date, and to the best of our knowledge, only one study has been published examining the overlap of psychiatric risk genes and pancreatitis pain. ${ }^{96}$ This study identified 15 loci significantly associated with constant severe pain in pancreatitis that were also previously associated with depression. ${ }^{96}$ Loci represent regions of DNA that have multiple SNPs and genes that tend to be transmitted over multiple generations together. So, it is usually not possible to pinpoint the actual risk factor(s) within a locus without extensive genomic tests - but the true risk factor and the SNP under evaluation are statistically and physically linked. Several of these $\mathrm{CP}$ pain loci are also associated with response to antidepressants as well. ${ }^{96}$ Identifying associations with pain in pancreatitis within psychiatric risk genes shows that the pain in pancreatitis is not only phenotypically associated with psychiatric disorders but also genotypically associated. ${ }^{96}$ These are exciting findings, but require replication and clinical studies to verify that the candidate risk loci do not represent a statistical aberration (false discovery), and so that the 
information can be moved into clinical practice as a target for precision therapies.

\section{Examples of Depression Risk Genes in Patients with CP and a Constant Severe Pain Phenotype}

We recently identified five candidate genes with variants in the coding or regulatory regions of the patient's DNA loci that were associated with the constant severe pain phenotype. $^{96}$ The location and function of these genes are briefly described.

The $\mathrm{ROBO}_{2}$ (roundabout guidance receptor 2) gene located at 3 p12.3 codes for the roundabout homolog 2 protein. $\mathrm{ROBO} 2$ is an immunoglobulin transmembrane receptor for slit homolog 2 and is most well known for mediating cell migration and axon guidance during development. However, ROBO2 plays an important part in maintaining inhibitory synapses in the adult ventral tegmental area, which is a source of dopamine production. ${ }^{111}$ Dysregulation of dopamine can have a profound effect on both pain and comorbid mood disorders. ${ }^{112}$

The CTNND2 (catenin delta 2, 5p15.2) gene encodes a protein in the armadillo/beta-catenin superfamily that is an adhesive junction-associated protein. The catenin delta 2 protein interferes with E-cadherin-based junctions and promotes cell spreading. During development, CTNND2 is highly expressed in the fetal brain in humans and is associated with neuronal adhesion, migration, and functioning. ${ }^{113}$ However, the Rat Genome Consortium was the first group to demonstrate that CTNND2 is associated with hippocampal volume and dysfunctional synapses in adult mice. Nivard et al replicated this finding in humans, showing an association between CTNND2 and anxiety and depression. ${ }^{113}$

The protein zeta-sarcoglycan coded by the $S G C Z(8 \mathrm{p} 22)$ is part of the sarcoglycan complex. $S G C Z$ is primarily expressed in the ovaries and brain. ${ }^{114}$ Bipolar disorder, schizophrenia, and major depressive disorder have all been associated with genes on chromosome 8 including $S G C Z$. $^{115}$ Additionally, $S G C Z$ is associated with antidepressant response and paliperidone efficacy in schizophrenia. ${ }^{116,117}$

Contactin 5 (CNTN5, 11q22.1) belongs to the immunoglobulin superfamily and contactin family that is involved with nervous system development. Contactin 5 is expressed mainly in the placenta, thyroid, and brain. ${ }^{114}$ CNTN5, an immunoglobulin cell adhesion protein, plays a role in axon connection in cortical neurons and neurite outgrowth. ${ }^{118}$
There is evidence that autism spectrum disorder phenotypes may result from increased activity of glutamatergic neurons that only have a single copy of CNTN5. ${ }^{119}$ The role in altered pain perception is not yet clear, but glutamate is a key neurotransmitter in sensory, spinal and cortical neurons.

The BAIAP2 (BAR/IMD domain-containing adaptor protein 2, 17q25.3) gene codes the brain-specific angiogenesis inhibitor 1-associated protein 2 , which is involved with G-protein coupling. The protein is involved in the regulation of neuronal membrane actin dynamics at excitatory synapses. In mice, deleting the gene homologous to $B A I A P 2$ increases the activity of NMDA receptors and results in abnormal behaviors. ${ }^{120}$ These behaviors are reversed in mice treated with memantine, an uncompetitive antagonist of NMDA receptors. BAIAP2 is also implicated in psychiatric disorders, such as ADHD, autism spectrum disorders, and schizophrenia in humans.

\section{Conclusions}

Severe pain in patients with CP can be identified and quantified, but tools to understand the underlying and variable mechanisms contributing to the severe pain experience in these patients are lacking. Thus, the most effective approach remains surgically removing some or all of the pancreas. In patients with complex and severe disease, it is likely that multiple overlapping mechanisms are simultaneously driving pain, anxiety and depression. New tools are needed to identify key pathogenic mechanisms, such as better questionnaires, QST and genetic testing - beginning with pharmacogenetics. New investigations of the overlap of pain, depression and anxiety demonstrate that multiple genetic risk loci for depression and anxiety are associated with constant severe pain experience and that the effects are manifest in the brain. Well-designed clinical trials that integrate clinical features, QST, genetics and psychological assessments with targeted treatment and assessment of responses are required for a quantum leap forward.

\section{Acknowledgments}

This research was partly supported by the NIDDK T32 DK063922-17 (EKD, DCW), NIH DK061451 (DCW), R21 DK098560 (DCW). Its contents are solely the responsibility of the authors and do not necessarily represent the official view of the NIH and National Pancreas Foundation. 


\section{Disclosure}

Prof. Dr. David C Whitcomb reports consulting for Abbvie, BioNTech, Nestle, Regeneron, and Samsung. He is also the co-founder, unpaid consultant for and may have equity with Ariel Precision Medicine. The authors report no other conflicts of interest in this work.

\section{References}

1. Gardner TB, Kennedy AT, Gelrud A, et al. Chronic pancreatitis and its effect on employment and health care experience: results of a prospective American multicenter study. Pancreas. 2010;39 (4):498-501. doi:10.1097/MPA.0b013e3181c5c693

2. Whitcomb DC, Frulloni L, Garg P, et al. Chronic pancreatitis: an international draft consensus proposal for a new mechanistic definition. Pancreatology. 2016;16(2):218-224. doi:10.1016/j. pan.2016.02.001

3. Zhan W, Akshintala V, Greer PJ, et al. Low serum trypsinogen levels in chronic pancreatitis: correlation with parenchymal loss, exocrine pancreatic insufficiency, and diabetes but not CT-based Cambridge severity scores for fibrosis. Pancreatology. 2020;20 (7):1368-1378. doi:10.1016/j.pan.2020.08.025

4. Bellin MD, Whitcomb DC, Abberbock J, et al. Patient and disease characteristics associated with the presence of diabetes mellitus in adults with chronic pancreatitis in the United States. $A m$ $J \quad$ Gastroenterol. 2017;112(9):1457-1465. doi:10.1038/ ajg.2017.181

5. Wilcox CM, Yadav D, Tian Y, et al. Chronic pancreatitis pain pattern and severity are independent of abdominal imaging findings. Clin Gastroenterol Hepatol. 2014;13(3):552-560. doi:10.1016/j.cgh.2014.10.015

6. Machicado JD, Amann ST, Anderson MA, et al. Quality of life in chronic pancreatitis is determined by constant pain, disability/ unemployment, current smoking, and associated co-morbidities. Am J Gastroenterol. 2017;112(4):633-642. doi:10.1038/ ajg. 2017.42

7. Cote GA, Yadav D, Abberbock JA, et al. Recurrent acute pancreatitis significantly reduces quality of life even in the absence of overt chronic pancreatitis. Am J Gastroenterol. 2018;113 (6):906-912. doi:10.1038/s41395-018-0087-7

8. Anderson MA, Akshintala V, Albers KM, et al. Mechanism, assessment and management of pain in chronic pancreatitis: recommendations of a multidisciplinary study group. Pancreatology. 2016;16(1):83-94. doi:10.1016/j.pan.2015.10.015

9. Drewes AM, Bouwense SAW, Campbell CM, et al. Guidelines for the understanding and management of pain in chronic pancreatitis. Pancreatology. 2017;17(5):720-731. doi:10.1016/j. pan.2017.07.006

10. Pasricha PJ. Unraveling the mystery of pain in chronic pancreatitis. Nat Rev Gastroenterol Hepatol. 2012;9(3):140-151. doi:10.1038/nrgastro.2011.274

11. D'Haese JG, Ceyhan GO, Demir IE, Tieftrunk E, Friess H. Treatment options in painful chronic pancreatitis: a systematic review. HPB. 2014;16(6):512-521. doi:10.1111/hpb.12173

12. Teo K, Johnson MH, Truter S, Pandanaboyana S, Windsor JA. Pain assessment in chronic pancreatitis: a comparative review of methods. Pancreatology. 2016;16(6):931-939. doi:10.1016/j. pan.2016.09.006

13. Phillips AE, Faghih M, Kuhlmann L, et al. A clinically feasible method for the assessment and characterization of pain in patients with chronic pancreatitis. Pancreatology. 2020;20(1):25-34. doi:10.1016/j.pan.2019.11.007
14. Cahen DL, Gouma DJ, Nio Y, et al. Endoscopic versus surgical drainage of the pancreatic duct in chronic pancreatitis. $N$ Engl $J$ Med. 2007;356(7):676-684. doi:10.1056/NEJMoa060610

15. Dite P, Ruzicka M, Zboril V, Novotny I. A prospective, randomized trial comparing endoscopic and surgical therapy for chronic pancreatitis. Endoscopy. 2003;35(7):553-558.

16. Clarke B, Slivka A, Tomizawa Y, et al. Endoscopic therapy is effective for patients with chronic pancreatitis. Clin Gastroenterol Hepatol. 2012;10(7):795-802. doi:10.1016/j.cgh.2011.12.040

17. Drewes AM, Kempeneers MA, Andersen DK, et al. Controversies on the endoscopic and surgical management of pain in patients with chronic pancreatitis: pros and cons! Gut. 2019;68(8):1343-1351. doi:10.1136/gutjnl-2019-318742

18. Bellin MD. A role for total pancreatectomy and islet autotransplant in the treatment of chronic pancreatitis. Am J Gastroenterol. 2018;113(3):324-326. doi:10.1038/ajg.2017.425

19. Smith SM, Dworkin RH, Turk DC, et al. The potential role of sensory testing, skin biopsy, and functional brain imaging as biomarkers in chronic pain clinical trials: IMMPACT considerations. J Pain. 2017;18(7):757-777. doi:10.1016/j.jpain.2017.02.429

20. Dorfman D, George MC, Robinson-Papp J, Rahman T, Tamler R, Simpson DM. Patient reported outcome measures of pain intensity: do they tell us what we need to know? Scand J Pain. 2016;11(1):73-76. doi:10.1016/j.sjpain.2015.12.004

21. Forsmark CE, Andersen DK, Farrar JT, et al. Accelerating the drug delivery pipeline for acute and chronic pancreatitis: summary of the working group on drug development and trials in chronic pancreatitis at the national institute of diabetes and digestive and kidney diseases workshop. Pancreas. 2018;47 (10):1200-1207. doi:10.1097/MPA.0000000000001174

22. Gillman A, Zhang D, Jarquin S, Karp JF, Jeong JH, Wasan AD. Comparative effectiveness of embedded mental health services in pain management clinics vs standard care. Pain Med. 2020;21 (5):978-991. doi:10.1093/pm/pnz294

23. Nelson S, Cunningham N. The impact of posttraumatic stress disorder on clinical presentation and psychosocial treatment response in youth with functional abdominal pain disorders: an exploratory study. Children (Basel). 2020;7(6). doi:10.3390/ children 7060056

24. Niculescu AB, Le-niculescu H, Levey DF, et al. Towards precision medicine for pain: diagnostic biomarkers and repurposed drugs. Mol Psychiatry. 2019;24(4):501-522. doi:10.1038/s41380-018-0345-5

25. Merskey H. Pain terms: a list with definitions and notes on usage. Recommended by the IASP subcommittee on taxonomy. Pain. 1979;6(3):249.

26. Teo K, Johnson MH, Drewes AM, Windsor JA. A comprehensive pain assessment tool (COMPAT) for chronic pancreatitis: development, face validation and pilot evaluation. Pancreatology. 2017;17(5):706-719. doi:10.1016/j.pan.2017.07.004

27. Wassef W, DeWitt J, McGreevy K, et al. Pancreatitis quality of life instrument: a psychometric evaluation. Am J Gastroenterol. 2016;111(8):1177-1186. doi:10.1038/ajg.2016.225

28. Ammann RW, Muellhaupt B. The natural history of pain in alcoholic chronic pancreatitis. Gastroenterology. 1999;116 (5):1132-1140. doi:10.1016/S0016-5085(99)70016-8

29. Mullady DK, Yadav D, Amann ST, et al. Type of pain, pain-associated complications, quality of life, disability and resource utilisation in chronic pancreatitis: a prospective cohort study. Gut. 2011;60(1):77-84. doi:10.1136/gut.2010.213835

30. Amodio A, De Marchi G, de Pretis N, et al. Painless chronic pancreatitis. Dig Liver Dis. 2020;52(11):1333-1337. doi:10.1016/ j.dld.2020.08.040

31. Olesen SS, Krauss T, Demir IE, et al. Towards a neurobiological understanding of pain in chronic pancreatitis: mechanisms and implications for treatment. Pain Rep. 2017;2(6):e625. doi:10.1097/PR9.0000000000000625 
32. Komara NL, Paragomi P, Greer PJ, et al. Severe acute pancreatitis: capillary permeability model linking systemic inflammation to multiorgan failure. Am J Physiol Gastrointest Liver Physiol. 2020;319(5):G573-G583. doi:10.1152/ajpgi.00285.2020

33. Bhardwaj P, Garg PK, Maulik SK, Saraya A, Tandon RK, Acharya SK. A randomized controlled trial of antioxidant supplementation for pain relief in patients with chronic pancreatitis. Gastroenterology. 2009;136(1):149-59e2. doi:10.1053/j. gastro.2008.09.028

34. Tandon RK, Garg PK. Oxidative stress in chronic pancreatitis: pathophysiological relevance and management. Antioxid Redox Signal. 2011;15(10):2757-2766. doi:10.1089/ars.2011.4115

35. Garg PK. Antioxidants for chronic pancreatitis: reasons for disappointing results despite sound principles. Gastroenterology. 2013;144(3):e19-20. doi:10.1053/j.gastro.2012.12.031

36. Bopanna S, Nayak B, Prakash S, Shalimar MSJ, Garg PK, Garg PK. Increased oxidative stress and deficient antioxidant levels may be involved in the pathogenesis of idiopathic recurrent acute pancreatitis. Pancreatology. 2017;17(4):529-533. doi:10.1016/j.pan.2017.06.009

37. Shalimar MS, Hasan A, Dhingra R, Garg PK, Garg PK. Longterm pain relief with optimized medical treatment including antioxidants and step-up interventional therapy in patients with chronic pancreatitis. J Gastroenterol Hepatol. 2017;32 (1):270-277. doi:10.1111/jgh.13410

38. Zhang L, RHt K, McNearney TA, Johnson MP, Westlund KN. Cannabinoid receptor 2 agonist attenuates pain related behavior in rats with chronic alcohol/high fat diet induced pancreatitis. Mol Pain. 2014;10:66. doi:10.1186/1744-8069-10-66

39. Michalski CW, Laukert T, Sauliunaite D, et al. Cannabinoids ameliorate pain and reduce disease pathology in cerulein-induced acute pancreatitis. Gastroenterology. 2007;132 (5):1968-1978. doi:10.1053/j.gastro.2007.02.035

40. Maselli DB, Camilleri M. Pharmacology, clinical effects, and therapeutic potential of cannabinoids for gastrointestinal and liver diseases. Clin Gastroenterol Hepatol. 2020;(in press). doi:10.1016/j.cgh.2020.04.020.

41. Croome KP, Tee M, Nagorney DM, et al. Pancreatoduodenectomy for chronic pancreatitis-results of a pain relief and quality of life survey 15 years following operation. $J$ Gastrointest Surg. 2015;19 (12):2146-2153. doi:10.1007/s11605-015-2928-7

42. Keck T, Wellner UF, Riediger $H$, et al. Long-term outcome after 92 duodenum-preserving pancreatic head resections for chronic pancreatitis: comparison of Beger and Frey procedures. J Gastrointest Surg. 2010;14(3):549-556. doi:10.1007/s11605009-1119-9

43. Keck T, Marjanovic G, Fernandez-del Castillo C, et al. The inflammatory pancreatic head mass: significant differences in the anatomic pathology of German and American patients with chronic pancreatitis determine very different surgical strategies. Ann Surg. 2009;249 (1):105-110. doi:10.1097/SLA.0b013e31818ef078

44. Kitano M, Gress TM, Garg PK, et al. International consensus guidelines on interventional endoscopy in chronic pancreatitis. Recommendations from the working group for the international consensus guidelines for chronic pancreatitis in collaboration with the international association of pancreatology, the American pancreatic association, the Japan pancreas society, and European pancreatic club. Pancreatology. 2020;20(6):1045-1055. doi:10.1016/j. pan.2020.05.022

45. Pham A, Forsmark C. Chronic pancreatitis: review and update of etiology, risk factors, and management. F1000Res. 2018;7:7. doi:10.12688/f1000research.12852.1

46. Di Sebastiano P, Fink T, Weihe E, et al. Immune cell infiltration and growth-associated protein 43 expression correlate with pain in chronic pancreatitis. Gastroenterology. 1997;112(5):1648-1655. doi:10.1016/S0016-5085(97)70047-7
47. Friess $\mathrm{H}$, Zhu ZW, Di Mola FF. Nerve growth factor and its high-affinity receptor in chronic pancreatitis. Ann Surg. 1999;230(5):615-624. doi:10.1097/00000658-199911000-00002

48. Friess H, Shrikhande S, Shrikhande M, et al. Neural alterations in surgical stage chronic pancreatitis are independent of the underlying aetiology. Gut. 2002;50(5):682-686. doi:10.1136/ gut.50.5.682

49. Ceyhan GO, Bergmann F, Kadihasanoglu M, et al. The neurotrophic factor artemin influences the extent of neural damage and growth in chronic pancreatitis. Gut. 2007;56(4):534-544. doi:10.1136/gut.2006.105528

50. Ceyhan GO, Demir IE, Rauch U, et al. Pancreatic neuropathy results in "neural remodeling" and altered pancreatic innervation in chronic pancreatitis and pancreatic cancer. Am J Gastroenterol. 2009;104(10):2555-2565. doi:10.1038/ajg.2009.380

51. Ceyhan GO, Demir IE, Maak M, Friess H. Fate of nerves in chronic pancreatitis: neural remodeling and pancreatic neuropathy. Best Pract Res Clin Gastroenterol. 2010;24 (3):311-322. doi:10.1016/j.bpg.2010.03.001

52. Kempeneers MA, Issa Y, Ali UA, et al. International consensus guidelines for surgery and the timing of intervention in chronic pancreatitis. Pancreatology. 2020;20(2):149-157. doi:10.1016/j. pan.2019.12.005

53. Mashayekhi R, Parekh VS, Faghih M, Singh VK, Jacobs MA, Zaheer A. Radiomic features of the pancreas on CT imaging accurately differentiate functional abdominal pain, recurrent acute pancreatitis, and chronic pancreatitis. Eur J Radiol. 2020;123:108778. doi:10.1016/j.ejrad.2019.108778

54. Robinson P, Perkins JC Jr. Approach to patients with epigastric pain. Emerg Med Clin North Am. 2016;34(2):191-210. doi:10.1016/j.emc.2015.12.012

55. Paolantonio P, Rengo M, Ferrari R, Laghi A. Multidetector CT in emergency radiology: acute and generalized non-traumatic abdominal pain. $B r \quad J$ Radiol. 2016;89(1061):20150859. doi:10.1259/bjr.20150859

56. Ecanow JS, Gore RM. Evaluating patients with left upper quadrant pain. Radiol Clin North Am. 2015;53(6):1131-1157. doi:10.1016/j.rcl.2015.06.003

57. Sharma A, Kandlakunta H, Nagpal SJS, et al. Model to determine risk of pancreatic cancer in patients with new-onset diabetes. Gastroenterology. 2018;155(3):730-9e3. doi:10.1053/j.gastro.201 8.05.023

58. Sharma A, Smyrk TC, Levy MJ, Topazian MA, Chari ST. Fasting blood glucose levels provide estimate of duration and progression of pancreatic cancer before diagnosis. Gastroenterology. 2018;155(2):490-500e2. doi:10.1053/j.gastro.2018.04.025

59. Andersen DK, Andren-Sandberg A, Duell EJ, et al. Pancreatitisdiabetes-pancreatic cancer: summary of an NIDDK-NCI workshop. Pancreas. 2013;42(8):1227-1237. doi:10.1097/ MPA.0b013e3182a9ad9d

60. Greenhalf W, Levy P, Gress T, et al. International consensus guidelines on surveillance for pancreatic cancer in chronic pancreatitis. Recommendations from the working group for the international consensus guidelines for chronic pancreatitis in collaboration with the international association of pancreatology, the American pancreatic association, the Japan pancreas society, and European pancreatic club. Pancreatology. 2020;20 (5):910-918. doi:10.1016/j.pan.2020.05.011

61. Faghih MPA, Kuhlmann LF, Afghani E, Drewes AM, Yadav D, Singh VK. Pancreatic QST differentiates chronic pancreatitis patients into distinct pain phenotypes independent of psychiatric comorbidities. Clin Gastroenterol Hepatol. 2020;In Press.

62. Apkarian AV, Bushnell MC, Treede RD, Zubieta JK. Human brain mechanisms of pain perception and regulation in health and disease. Eur J Pain. 2005;9(4):463-484. 
63. Apkarian AV, Baliki MN, Geha PY. Towards a theory of chronic pain. Prog Neurobiol. 2009;87(2):81-97. doi:10.1016/j.pneu robio.2008.09.018

64. Apkarian AV, Hashmi JA, Baliki MN. Pain and the brain: specificity and plasticity of the brain in clinical chronic pain. Pain. 2011;152(3 Suppl):S49-64. doi:10.1016/j.pain.2010.11.010

65. Simons LE, Elman I, Borsook D. Psychological processing in chronic pain: a neural systems approach. Neurosci Biobehav Rev. 2014;39:61-78.

66. Baliki MN, Petre B, Torbey S, et al. Corticostriatal functional connectivity predicts transition to chronic back pain. Nat Neurosci. 2012;15(8):1117-1119. doi:10.1038/nn.3153

67. Mansour AR, Baliki MN, Huang L, et al. Brain white matter structural properties predict transition to chronic pain. Pain. 2013;154(10):2160-2168. doi:10.1016/j.pain.2013.06.044

68. Hashmi JA, Baliki MN, Huang L, et al. Shape shifting pain: chronification of back pain shifts brain representation from nociceptive to emotional circuits. Brain. 2013;136(Pt 9):2751-2768. doi:10.1093/brain/awt211

69. Mutso AA, Petre B, Huang L, et al. Reorganization of hippocampal functional connectivity with transition to chronic back pain. $J$ Neurophysiol. 2014;111(5):1065-1076. doi:10.1152/jn.00 611.2013

70. Seminowicz DA, Labus JS, Bueller JA, et al. Regional gray matter density changes in brains of patients with irritable bowel syndrome. Gastroenterology. 2010;139(1):48-57e2. doi:10.1053/ j.gastro.2010.03.049

71. Kim M, Mawla I, Albrecht DS, et al. Striatal hypofunction as a neural correlate of mood alterations in chronic pain patients. Neuroimage. 2020;211:116656. doi:10.1016/j.neuroimag e. 2020.116656

72. Dammann J, Klepzig K, Schenkenberger E, Kordass B, Lotze M. Association of decrease in insula fMRI activation with changes in trait anxiety in patients with craniomandibular disorder (CMD). Behav Brain Res. 2020;379:112327. doi:10.1016/j.bbr.201 9.112327

73. Bingel U, Wanigasekera V, Wiech $\mathrm{K}$, et al. The effect of treatment expectation on drug efficacy: imaging the analgesic benefit of the opioid remifentanil. Sci Transl Med. 2011;3(70):70ra14. doi:10.1126/scitranslmed.3001244

74. Boettger MK, Schwier C, Bar KJ. Sad mood increases pain sensitivity upon thermal grill illusion stimulation: implications for central pain processing. Pain. 2011;152(1):123-130. doi:10.1016/j.pain.2010.10.003

75. Boettger MK, Grossmann D, Bar KJ. Thresholds and perception of cold pain, heat pain, and the thermal grill illusion in patients with major depressive disorder. Psychosom Med. 2013;75 (3):281-287. doi:10.1097/PSY.0b013e3182881a9c

76. Bilek E, Zang Z, Wolf I, et al. Neural network-based alterations during repetitive heat pain stimulation in major depression. Eur Neuropsychopharmacol. 2019;29(9):1033-1040. doi:10.1016/j. euroneuro.2019.06.011

77. Etkin A. Functional neuroanatomy of anxiety: a neural circuit perspective. Curr Top Behav Neurosci. 2010;2:251-277.

78. Fox ME, Lobo MK. The molecular and cellular mechanisms of depression: a focus on reward circuitry. Mol Psychiatry. 2019;24 (12):1798-1815.

79. Knowland D, Lim BK. Circuit-based frameworks of depressive behaviors: the role of reward circuitry and beyond. Pharmacol Biochem Behav. 2018;174:42-52. doi:10.1016/j.pbb.2017.12.010

80. Strigo IA, Simmons AN, Matthews SC, Craig AD, Paulus MP. Association of major depressive disorder with altered functional brain response during anticipation and processing of heat pain. Arch Gen Psychiatry. 2008;65(11):1275-1284. doi:10.1001/ archpsyc.65.11.1275
81. Petrov MS, Yadav D. Global epidemiology and holistic prevention of pancreatitis. Nat Rev Gastroenterol Hepatol. 2019;13 (3):175-184. doi:10.1038/s41575-018-0087-5

82. Whitcomb DC, North American Pancreatitis Study G. Pancreatitis: TIGAR-O version 2 risk/etiology checklist with topic reviews, updates, and use primers. Clin Transl Gastroenterol. 2019;10(6):e00027. doi:10.14309/ctg.00000000 00000027

83. Whitcomb DC. Primer on precision medicine for complex chronic disorders. Clin Transl Gastroenterol. 2019;10(7):e00067. doi:10.14309/ctg.0000000000000067

84. Kleeff J, Whitcomb DC, Shimosegawa T, et al. Chronic pancreatitis. Nat Rev Dis Primers. 2017;3:17060.

85. Gardner TB, Adler DG, Forsmark CE, Sauer BG, Taylor JR, Whitcomb DC. ACG clinical guideline: chronic pancreatitis. Am J Gastroenterol. 2020;115(3):322-339. doi:10.14309/ajg.0000000 000000535

86. Lloyd RA, Hotham E, Hall C, Williams M, Suppiah V. Pharmacogenomics and patient treatment parameters to opioid treatment in chronic pain: a focus on morphine, oxycodone, tramadol, and fentanyl. Pain Med. 2017;18(12):2369-2387. doi: $10.1093 / \mathrm{pm} / \mathrm{pnw} 317$

87. Fairbanks J, Umbreit A, Prakash Kolla B, et al. Evidenced-based pharmacotherapies for alcohol use disorder: clinical pearls. Mayo Clin Proc. 2020;95(9):1964-1977. doi:10.1016/j.mayoc p. 2020.01 .030

88. Gottschalk MG, Domschke K. Genetics of generalized anxiety disorder and related traits. Dialogues Clin Neurosci. 2017;19 (2):159-168.

89. Rossow KM, Aka IT, Maxwell-Horn AC, Roden DM, Van Driest SL. Pharmacogenetics to predict adverse events associated with antidepressants. Pediatrics. 2020;146(6):e20200957. doi:10.1542/peds.2020-0957

90. Milosavljevic F, Bukvic N, Pavlovic Z, et al. Association of CYP2C19 and CYP2D6 poor and intermediate metabolizer status with antidepressant and antipsychotic exposure: a systematic review and meta-analysis. JAMA Psychiatry. 2020;25:e203643.

91. Bousman CA, Bengesser SA, Aitchison KJ, et al. Review and consensus on pharmacogenomic testing in psychiatry. Pharmacopsychiatry. 2020;(Online ahead of print).

92. Shelton CA, Whitcomb DC. Precision medicine for pancreatic diseases. Curr Opin Gastroenterol. 2020;36(5):428-436.

93. Whitcomb DC, Shimosegawa T, Chari ST, et al. International consensus statements on early chronic Pancreatitis. Recommendations from the working group for the international consensus guidelines for chronic pancreatitis in collaboration with The International Association of Pancreatology, American Pancreatic Association, Japan Pancreas Society, PancreasFest Working Group and European Pancreatic Club. Pancreatology. 2018;S1424-3903(18):30113.

94. Outcalt SD, Kroenke K, Krebs EE, et al. Chronic pain and comorbid mental health conditions: independent associations of posttraumatic stress disorder and depression with pain, disability, and quality of life. J Behav Med. 2015;38(3):535-543.

95. Bair MJ, Robinson RL, Katon W, Kroenke K. Depression and pain comorbidity: a literature review. Arch Intern Med. 2003;163 (20):2433-2445.

96. Dunbar E, Greer PJ, Melhem N, et al. Constant-severe pain in chronic pancreatitis is associated with genetic loci for major depression in the NAPS2 cohort. $J$ Gastroenterol. 2020;55 (10):1000-1009.

97. McIntosh AM, Hall LS, Zeng Y, et al. Genetic and environmental risk for chronic pain and the contribution of risk variants for major depressive disorder: a family-based mixed-model analysis. PLoS Med. 2016;13(8):e1002090. 
98. Sheng J, Liu S, Wang Y, Cui R, Zhang X. The link between depression and chronic pain: neural mechanisms in the brain. Neural Plast. 2017;2017:9724371.

99. Phillips AE, Faghih M, Drewes AM, Singh VK, Yadav D, Olesen SS. Psychiatric comorbidity in patients with chronic pancreatitis associates with pain and reduced quality of life. Am $J$ Gastroenterol. 2020;115(12):2077-2085.

100. Balliet WE, Edwards-Hampton S, Borckardt JJ, et al. Depressive symptoms, pain, and quality of life among patients with nonalcohol-related chronic pancreatitis. Pain Res Treat. 2012;2012:978646. doi:10.1155/2012/978646

101. Gilman SE, Abraham HD. A longitudinal study of the order of onset of alcohol dependence and major depression. Drug Alcohol Depend. 2001;63(3):277-286. doi:10.1016/S0376-8716(00) 00216-7

102. Fergusson DM, Boden JM, Horwood LJ. Tests of causal links between alcohol abuse or dependence and major depression. Arch Gen Psychiatry. 2009;66(3):260-266. doi:10.1001/archgenp sychiatry.2008.543

103. Hasin DS, Grant BF. Major depression in 6050 former drinkers: association with past alcohol dependence. Arch Gen Psychiatry. 2002;59(9):794-800. doi:10.1001/archpsyc.59.9.794

104. Conway KP, Compton W, Stinson FS, Grant BF. Lifetime comorbidity of DSM-IV mood and anxiety disorders and specific drug use disorders: results from the national epidemiologic survey on alcohol and related conditions. J Clin Psychiatry. 2006;67 (2):247-257. doi:10.4088/JCP.v67n0211

105. Grant BF, Goldstein RB, Chou SP, et al. Sociodemographic and psychopathologic predictors of first incidence of DSM-IV substance use, mood and anxiety disorders: results from the wave 2 national epidemiologic survey on alcohol and related conditions. Mol Psychiatry. 2009;14(11):1051-1066. doi:10.1038/ mp. 2008.41

106. Boden JM, Fergusson DM. Alcohol and depression. Addiction. 2011;106(5):906-914. doi:10.1111/j.1360-0443.2010.03351.x

107. Yadav D, Hawes RH, Brand RE, et al. Alcohol consumption, cigarette smoking, and the risk of recurrent acute and chronic pancreatitis. Arch Intern Med. 2009;169(11):1035-1045. doi:10.1001/archinternmed.2009.125

108. Han S, Patel B, Min M, et al. Quality of life comparison between smokers and non-smokers with chronic pancreatitis. Pancreatology. 2018;18(3):269-274. doi:10.1016/j.pan.2018.0 2.012

109. Han S, Kheder J, Bocelli L, et al. Smoking cessation in a chronic pancreatitis population. Pancreas. 2016;45(9):1303-1308. doi:10.1097/MPA.0000000000000641
110. Thompson JM, Neugebauer V. Cortico-limbic pain mechanisms. Neurosci Lett. 2019;702:15-23. doi:10.1016/j.neulet.2018.11.037

111. Gore BB, Miller SM, Jo YS, et al. Roundabout receptor 2 maintains inhibitory control of the adult midbrain. Elife. 2017;6:6. doi:10.7554/eLife. 23858

112. Serafini RA, Pryce KD, Zachariou V. The mesolimbic dopamine system in chronic pain and associated affective comorbidities. Biol Psychiatry. 2020;87(1):64-73. doi:10.1016/j.biopsyc h.2019.10.018

113. Nivard MG, Mbarek H, Hottenga JJ, et al. Further confirmation of the association between anxiety and CTNND2: replication in humans. Genes Brain Behav. 2014;13(2):195-201. doi:10.1111/ gbb. 12095

114. Murphy M, Brown G, Wallin C, et al. Gene help: integrated access to genes of genomes in the reference sequence collection. 20062019 [cited 2019]. In: gene help [Internet]. Bethesda (MD): National Center for Biotechnology Information (US). [cited 2019]. Available from: https://www.ncbi.nlm.nih.gov/books/ NBK3841/. Accessed February 22, 2021.

115. Chen X, Long F, Cai B, et al. Relationship for schizophrenia, bipolar, and major depressive disorder. Part 8: a hint from chromosome 8 high density association screen. Mol Neurobiol. 2017;54(8):5868-5882. doi:10.1007/s12035-016-0102-1

116. Fabbri C, Kasper S, Kautzky A, et al. Genome-wide association study of treatment-resistance in depression and meta-analysis of three independent samples. Br J Psychiatr. 2019;214(1):36-41. doi:10.1192/bjp.2018.256

117. Li Q, Wineinger NE, Fu DJ, et al. Genome-wide association study of paliperidone efficacy. Pharmacogenet Genomics. 2017;27 (1):7-18. doi:10.1097/FPC.0000000000000250

118. van Daalen E, Kemner C, Verbeek NE, et al. Social responsiveness scale-aided analysis of the clinical impact of copy number variations in autism. Neurogenetics. 2011;12(4):315-323. doi:10.1007/s10048-011-0297-2

119. Deneault E, Faheem M, White SH. et al. CNTN5(-)(/+) or EHMT2(-)(/+)human iPSC-derived neurons from individuals with autism develop hyperactive neuronal networks. eLife;2019. 8. doi:10.7554/eLife.40092

120. Kang J, Park H, Kim E. IRSp53/BAIAP2 in dendritic spine development, NMDA receptor regulation, and psychiatric disorders. Neuropharmacology. 2016;100:27-39. doi:10.1016/j. neuropharm.2015.06.019
Journal of Pain Research

\section{Publish your work in this journal}

The Journal of Pain Research is an international, peer reviewed, open access, online journal that welcomes laboratory and clinical findings in the fields of pain research and the prevention and management of pain. Original research, reviews, symposium reports, hypothesis formation and commentaries are all considered for publication. The manuscript management system is completely online and includes a very quick and fair peer-review system, which is all easy to use. Visit http:// www.dovepress.com/testimonials.php to read real quotes from published authors. 